\title{
Cultivating Creativity: Insights from German Local Governments about the Drivers and Barriers of Change
}

\author{
Hans Christian Klein \\ Universität Siegen \\ christian.klein@uni-siegen.de
}

\author{
Frederike Marie Oschinsky \\ Universität Siegen \\ frederike.oschinsky@uni-siegen.de
}

\author{
Sarah Rubens \\ Universität Siegen \\ sarah.rubens@student.uni-siegen.de
}

\begin{abstract}
There is a tremendous need for creative problem solving and innovation. While creativity is considered as a crucial resource in the private sector and in startups, creative methods such as design thinking are rarely used as a systematic approach for public innovation. Thus, individual creative work practices with their drivers and barriers are not yet fully understood in public organizations. We start to fill this gap by giving an overview on related work as well as on the foundations of creativity. Next, we present best practices from German local governments. We conduct a focus group interview and illustrate preliminary results. By doing so, we identify four main themes that determine the drivers and barriers when cultivating creativity in the public sector (i.e., creativity and self-efficacy, complexity and application, clearance, mindset). As a conclusion, we discuss our results and show avenues for further research.
\end{abstract}

\section{Introduction}

In public sector, there is tremendous need for creative problem solving and innovation. For instance, evolving Smart Cities seek to answer questions about urbanization and globalization on all levels and with multiple stakeholders [16]. Public administrations are faced with the need to improve the economy, governance, mobility, environment and living in their cities $[3,9,13]$. They increasingly intend to solve their challenges and address the digital transformation with creative and agile methods, but they are often only at the beginning $[22,23]$.

New social challenges (e.g., pandemics like Covid19) show that governments have to be resilient and agile in a way that they have to adapt to new situations more often and much faster than before [39]. These new challenges have to be tackled from all governments independently from their size, location and approach (techno centric or human centric) by implementing new technologies and innovations - in other words: ideas
[18]. Also, digital services and multisector approaches for co-creation are under development in order to deliver promising services and thus increased value for citizens. Existing solutions fail and the need for new approaches and work practices is high [22].

Creativity is precedent for creative problem solving and innovation in organizations and cities. Thus, creative work practices offer a high chance for the public sector to tackle today's challenges and the need to innovate $[5,33]$. We see the concept of creativity as broader as it is colloquially used, as we do not limit our understanding to haphazard Eureka-moments. Instead, we approach creativity from a psychological perspective and see it as cognitive process with an interplay between flexibility ("the ease with which people can switch to a different approach or consider a different perspective" [26]) and persistence ("the degree of sustained and focused task-directed cognitive effort" [26]). Individual creativity is the origin and starting point for innovation - also in collaborative settings. While the state of knowledge is rich about public innovation [36], the understanding of drivers and barriers of individual creativity in the public sector is rare.

Private sector and start-ups in particular use this twofold understanding of creativity with its associated techniques and mindsets to develop innovation and solve problem with the power of creativity [15]. Their idea of creative work practices differs from the idea of optimized processes and incremental improvement by going new ways with the help of new methods like design thinking [5]. In the public sector, innovation is not driven by competition or profit motives [36], what makes it different from private sector innovation. There are different strategies to foster public sector innovation. Collaborative settings are described as most promising according to Torfing [2019]. However, as the individual creativity is the origin of public innovation, it will be a decisive need of collaboration to foster individual creativity. While these new methods are not clearly defined and allow for different interpretations, they are widely understood as (a) a clear description of a process, (b) a new mindset for evaluating and doing things, or (c) a toolbox to use different instruments and techniques 
[38]. There are different methods in use, which all have a three-step approach in common. Step 1, analyzing; Step 2, ideation; Step 3, testing [19]. Around these methods and steps, there are several techniques (e.g., brainstorming, prototyping, etc.) in order to enhance creativity on the individual, group and organizational level.

It is important to understand the drivers and barriers in German local governments, as the mechanisms in public sector are different due to the fact that "...the absence of competition and profit motives creates different conditions for innovation in the public sector" $[36$, p.4]. In order to understand the drivers and barriers of adopting and cultivating creativity in German local governments, it seems to be helpful to understand where these creative techniques and methods come from. Because it makes a difference if a work practice or method is rooted in a discipline or whether it is adopted to a domain, we will use an example of a popular creative problem-solving method. Using the example of design thinking illustrates that the idea of creative problem solving is a methodological approach that origins from product design and architecture [30]. Adopting design-oriented methods in the business sector went along with a human-centered approach where the user and user needs became focal points [38]. The third and the most current stream of adopting design thinking is about social innovation [20]. In this line of argument, creativity is seen as key to innovation.

Against the theoretical background and initial practical work, a few questions remain unanswered: Which drivers and barriers determine the governmental use of creative methods like design thinking? What are the drivers and barriers when cultivating creativity in German local governments? Answering these questions help understand and further shape the adoption of creativity in the public sector.

To answer our research question, this work is structured as follows: First, we present an overview on creativity and the current state in German local governments. Second, we give an overview on the methodological approach. Third, as our research is an initial step, we present preliminary findings of our prestudy. Finally, this paper ends with discussing our findings and by providing an outlook for future research.

\section{Related Work}

\subsection{Creativity}

Creativity is a multifaceted cognitive phenomenon and has been studied in various disciplines, including psychology, sociology, organizational behavior research, Information Systems (IS), and the humanities
[32]. In IS research, authors have discussed this topic since the early 90s, however, Couger [6] stated that it is still under-researched in the respective domain [32]. Since then, the research of creativity is a permanent stream of interest [17]. The common characterization of creativity is to create or produces something new, that had not existed before, or in other words, "creativity typically emerges from discovering new associations between previously disparate things" [24]. We define individual creativity as a necessary prerequisite for innovation and want to contribute to existing knowledge by examining the individual conditions of creativity and ideation.

One model to understand the complexity of creativity is proposed by Rhodes [29] and it is called 4Ps model. The model proposes different perspectives on creativity, namely the process, the person, the product, and the press or environment behind the phenomena of creativity. In contrast to other theories, the model provides a broad understanding and a holistic approach, that other theories such as the Cognitive Network Model (CNM), the Adaptive Control of Thought theory (ACT) and the Search of Associative Memory theory (SAM) did not offer at this point. After presenting the initial work by Rhodes, we will transfer these perspectives to the public sector, because this opens areas for action. We identify public sector specific features concerning the 4-Ps.

The perspective on the creative person shows that there are differences on the individual level [29]. It is important that the creative abilities on that level can be trained and learned and are not only determined by gens - which is a widely known mindset [6, 28]. This perspective opens opportunities for IS research by enhancing creativity through the use of technology or software [6]. Looking at public sector specific features, the employees in this sector are traditionally not trained in creative techniques. Whilst creative methods already reached the business world, employees in the public sector are not seen as designers or agile thinkers, because there was no need for that before. However, governments reach out for creative problem solving and innovation. Thus, there is a huge potential of enhancing creativity on the individual level by using software or stimulating creativity by public management.

The creative process is omnipresent in contemporary creative techniques like design thinking. It is about the process which can be taught, learned, and thus communicated [29]. In IS research, this perspective can value the opportunity to implement skill-enhancing support systems incorporating strategies and software tools [24]. Again, looking at this perspective from the public sector's point of view, skill-enhancing techniques, which are supported by strategies and software tools, seem to be worthwhile. Governments in 
the digital age are highly interconnected. Co-creation is one example of multi-sectoral and cross-juristical networks of collaboration [7]. Thus, people with different backgrounds are increasingly working together. Understanding common grounds and processes can help both individual with different background and diverse teams to collaborate. Moreover, at the organizational level, a shared understanding facilitates work routines. Because administrations have become diverse, interdisciplinary and open-minded work settings need to be designed in order to enhance creative output.

The creative product is the outcome of the creative process, which leads to a novel and original idea. Thus, the idea can be seen as a created artefact, which can be a product, service, business-model, or even a strategy [4]. The outcome can be evaluated and tested, which is a good point of departure for IS research to evaluate and measure the creative product. Transferring this perspective to the public sector shows that the development of new services is a corner stone of egovernment and digital government value creation [2, 22, 23]. Against this background, there are creative methods like service design thinking, which were adopted to and applied in the public sector [7, 34]. Another example are digital service teams, which were implemented in order to enhance the development of new services [22]. In addition, we can find different streams where products are present. For example, on the website https://open.gov.sg/ Singapore presents its work under the slogan "Build Technology for the Public Good" [40]. In other countries, such as Germany, this perspective manifests itself in policies, which implement the user- and customer-orientation as well as new public management approaches, and at the same time adopt perspectives from the private sector [31].

Business-models in the sense of public sector products also play a role. Through the development of smart cities and the co-creation between different sectors, there can emerge different opportunities concerning creativity towards business-models. One is the opportunity for public sector spin-offs or new public sector agency, where the understanding and creation of new business models takes place [11]. Another one is the need for understanding business models in order to shape policies and strategies that foster innovation and new business models in order to stimulate new industries as value for society [14]. Also strategies do play a major role in public sector, e.g., smart city strategies. From traditional urban planning- and spatial strategies we know that the development of smart cities requires strategic work [25]. The transformation of governmental organizations needs these strategies in order to transform purposefully [12].
Finally, the creative press or environment describes the organizational influence of values and norms, which can support or suppress creativity in organizations [6]. Opportunities and challenges for IS research are various in this respect, because of the disperse use of technologies and related organizational policies. In the case of the public sector, creativity and the related norms and values of an open-minded work culture do differ from what a lot of traditional professions learned and what traditional skills such as optimization built on [37]. One example is how to deal with failure. While it is important not to make mistakes in core-processes in traditional environments, it is absolutely worthful to make mistakes and learn from them in a creative culture. The ability of ambidexterity is another important aspect to handle both core-processes and new ways of work. Because of the digital transformation, it is important to be efficient in core-processes and to frequently find new ways and solutions. The influence of the press or environment does also play a major role [1] by giving creative abilities space.

\subsection{Exploring German Local Governments}

In Germany, there are many municipalities and city administrations that run creativity projects and use creative methods. Now, we present some examples from German local governments, which are regarded as best practice examples, and have served as pioneers for other large projects. They might have a special appeal due to the size of the city or its regional character.

Office for unsolvable tasks. The Office for Unsolvable Tasks (German: "Amt für unlösbare Aufgaben") is an interdisciplinary team consisting of a theatre-maker, an architect, a music producer and an urban developer, which came together during the PHASE XI project that has been initiated by the Cultural and Creative Industries Initiative of the German Federal Government and the Federal Competence Centre for Cultural and Creative Industries. The office develops creative solutions for bureaucratic processes. Topics from business, politics and society are examined from the perspective of eleven creative industries in a total of eight labs throughout Germany. Leonie Pichler, theatre director and member of the Office for Unresolvable Tasks, summarizes the central aim in providing answers on how to get humanity, an appealing language, appreciation, design, humor and identification into bureaucracy [101].

GovLab Arnsberg. A similar approach is the governance laboratory (GovLab) in Arnsberg. The initiative was founded in April 2018 in the district government of Arnsberg, which is a central authority in the state of North Rhine-Westphalia. The principles of the innovation lab will be transferred to the 
administration and agile methods will be used to make life easier for citizens, communities and employees. The aim is to make administration as simple as possible. Some projects are submitted by core administration staff; others are the result of events organized by the lab. The projects always include diverse project teams. They have a workshop room as well as templates, method descriptions, prototyping software, and even chatbots $[102,103]$.

Dinslaken. The metropolitan region Rhine-Ruhr is one of the largest conurbations in Europe. Because the cities are becoming crowded as the population grows, questions of the reorganization and restructuring of areas and spaces in cities need to be tackled. Space as a resource plays a major role as one of five core themes of CREATIVE.NRW (Cluster of Cultural and Creative Industries in North Rhine-Westphalia). In 2005, the Lohberg mine was closed. In the following years, a design workshop entitled 'Perspectives for DinslakenLohberg' was set up to collect the concerns, criticism and wishes of citizens and local actors. The project was about restructuring, reorganizing and reusing space. Subsequently, several event-related citizens' workshops on structural planning were held. The results were incorporated into a structural plan. In 2009 and 2010, a framework was developed, which divides the area into a residential area, the core area 'Creative Quarter Lohberg' and a commercial area. A park and a foot and cycle path, the serve as a connection. These goals were achieved with multiple forms of citizen participation. In workshops with international experts and creative companies, a mission statement was developed. Furthermore, there is a debating platform for debating future topics. There are discussions on fundamental tasks of location development, aimed at experts as well as citizens. In addition, creative people from Dinslaken and the surrounding areas visit the event 'Idea meets market' organized in the form of a world café and used as an opportunity to exchange ideas. It dealt with questions like "How do young companies manage to successfully position themselves on the market?".

Munich. In 2018, representatives got involved in a three-day Design Sprint. The participating departments were the E-/Open-Government \& Smart City unit, the Department of Social Affairs and the Department of Urban Planning and Building Regulations of the City of Munich. All of them brought questions to the table, which were then addressed with the help of moderators. A design sprint is about generating and validating ideas and solutions as quickly as possible. Approaches such as Design Thinking, Service Design or agile product development are used. A major advantage is that measurable and user-centered results are obtained within a very short time. Through a mixture of group and individual work and the deliberate use of time pressure as a creativity technique, Design Sprint teams are extremely productive. The administration in Munich used the Design Sprint as an inspiration to shorten lengthy processes with "comparatively little resources and time, to deal with questions openly and across departments, and to develop concrete, user-oriented solutions" [104]. The participants looked at questions from different perspectives and put themselves in the position of their users (citizens or colleagues). First insights were derived and solution spaces were defined. Finally, prototypes were created and tested on users. The feedback enabled the participants to revise their solution approaches and to plan the next steps.

Heidelberg. The municipal administration of the city of Heidelberg is considered a best practice example for administrations in Germany when it comes to creative techniques. The city does a lot to make communication as transparent and simple as possible. There are committees, a staff newspaper, information events and one-on-one meetings with employees [105]. The resource of space is also put to new uses: The "office of the future was designed as a place of mutual appreciation" [106]. For example, the is an armchair with an integrated table. Raised rotary chairs are intended to enable conversations literally at eye level. This room concept has been tested by citizens and said to be a good idea during the long night of bureaucracy, another idea from Heidelberg. Since 2017, the administration opens from 8 to $11 \mathrm{pm}$ to reach people who have to work during normal opening hours [107]. Somehow, Heidelberg resembles an up-to-date company. Citizens are regarded as customers to think and act in a solution-oriented manner and to be able to offer the best possible service. In areas such as design and digitization, the administration works with experts from the private sector, who are hired on a part-time or as freelancers. In this way, the administration becomes open to modern topics, methods and working methods. Some of the methods are team boards, the development of personas and design thinking. In addition, there is further training, a flexible pension program, and great efforts to be family-friendly. Home office can be negotiated individually. Feedback discussions are held with all employees several times a year.

\section{Methodological Approach}

\subsection{Research Design}

Case study research. Since our research is intended to gain insights into government and its digital transformation, our study is highly explorative and specified to the governmental context. As the situation in public sector organizations is dynamic, because of e- 
government legislation and internal change and smart city transformation an explorative case study approach seemed promising [8].

Focus group approach. Doing focus groups as qualitative method is underestimated and its potential is not fully exhausted $[27,35]$. In our case, interaction and the deep discussion on a topic based on personal experience is considered as valuable. Thus, we decided to conduct a focus group interview. The discussion helped make social dynamics, consensus and conflicts observable. The participants empowered each other and brought broad insights to the table [35]. We were able to collect rich data in a short time period - "attitudes, feelings, beliefs, experiences, and reactions in a way that is not feasible using other field methods" [35].

Case description. The participants were part of a larger project in which the municipalities of a district reconvene on a regular basis with the goal to develop a shared digitization strategy. Their professional background and training is multidisciplinary. The topics of the overall project are building competencies (workshops which are offered to the mayors, administrative boards and executives are directed), developing strategy (developing a digitization strategy), implementing projects (develop concrete, joint projects to initiate and accompany digitization projects), and supporting activities (activities to promote the networking of the individual actors in the district and to provide opportunities for further training). Currently, the competencies had been completed and the strategy had been developed. Projects are being assembled and the project implementing is taking place.

\subsection{Data and Analysis}

We conducted a focus group interview with employees from four different public sector organizations $(n=4$, all male) to identify drivers and barriers of a creativity in their domain. The sample of organizations obtained three municipalities (population 104.000/25.000/7.000) and one district (280.000), which includes the municipalities. The sample covered the most common classes of municipalities in Germany (Kleinstadt - small city up to 20.000 inhabitants, Mittelstadt - medium city up to 100.000 inhabitants, Großstadt - large city from 100.000 inhabitants) and thus gives a good starting point. The participants had positions within their organization, which include aspects of smart city or digital transformation. The focus group interview was held virtually with the Webex platform by Cisco.

The workshop was divided into three phases. First, the moderator gave an overview about creativity and about common stimuli and psychological factors (creativity as something you can learn). There are two kind of enhancing individual creativity. Priming (unconscious) and stimuli (conscious) are hints to be more creative [26,32]. In order to understand the mechanisms, we used stimuli to introduce the concept in our study. Second, we conducted two ideation tasks. The first one happened without stimuli and the second one with stimuli. The visual stimulus (11 design heuristics/design principles - guidance for idea generation) was presented as text and icons (see table 1). The second one was designed in a similar fashion, but now the participants had the same understanding of ideation. We choose ideation because it is core of creative problem-solving tasks. In the third phase, we discussed whether and how creativity could be helpful not only for doing ideation tasks in public administrations, but for a 'real' design or problemsolving task for governmental products, services, processes, strategies or even business-models in daily live, i.e. authentical problem-solving tasks. By presenting and discussing the results of phase 2 and discussing the questions of phase 3 , we achieved an ongoing discussion encouraging the experts to think and reflect about their everyday practices and beyond. We collected the data with audio recording and transcription, prepared by one of the authors. Based on this data, we identified different themes presented in table 2. Analyzing the data was performed by two of the authors in several iterative steps.

\begin{tabular}{|l|l|l|}
\hline $\begin{array}{l}\text { Heuristic/ } \\
\text { principles }\end{array}$ & Description \\
\hline $\begin{array}{l}\text { Add features } \\
\text { from nature }\end{array}$ & $\begin{array}{l}\text { The object mimics } \\
\text { natural features or helps } \\
\text { to mimic natural features }\end{array}$ & $\begin{array}{l}\text { Icon } \\
\text { something or helps } \\
\text { something to be attached }\end{array}$ \\
\hline $\begin{array}{l}\text { Attach product } \\
\text { to user }\end{array}$ & $\begin{array}{l}\text { The object helps to } \\
\text { change flexibility or is } \\
\text { flexible }\end{array}$ & $\begin{array}{l}\text { The object fits within a } \\
\text { specific context }\end{array}$ \\
\hline $\begin{array}{l}\text { Change } \\
\text { flexibility }\end{array}$ & $\begin{array}{l}\text { The object can be used to } \\
\text { lift or lower something } \\
\text { or can be lifted or } \\
\text { lowered }\end{array}$ & $\begin{array}{l}\text { The object can be used to } \\
\text { extend the assumed size } \\
\text { of something or can be } \\
\text { extended }\end{array}$ \\
\hline Contextualize \\
Elevate or
\end{tabular}




\begin{tabular}{|l|l|l|}
\hline $\begin{array}{l}\text { Mirror or } \\
\text { array }\end{array}$ & $\begin{array}{l}\text { The object can be used to } \\
\text { something because it is } \\
\text { mirrored or arrayed } \\
\text { along a central axis or } \\
\text { pattern }\end{array}$ & $\begin{array}{l}\text { The object can be used } \\
\text { by being flipped } \\
\text { (vertical/ horizontal) or } \\
\text { help to flip something }\end{array}$ \\
\hline Reorient & $\begin{array}{l}\text { The object can be used } \\
\text { by being repeated or help } \\
\text { to repeat something }\end{array}$ & $\begin{array}{l}\text { The object can be used } \\
\text { by being separated or } \\
\text { help to separate }\end{array}$ \\
\hline Repeat &
\end{tabular}

Table 1. Design Heuristics

\section{Findings}

In this chapter, we present our findings structured in four emerged themes. The quotations were translated into English with minor adjustments.

\begin{tabular}{|l|l|}
\hline Theme & $\begin{array}{l}\text { Definition } \\
\text { (provided by the authors) }\end{array}$ \\
\hline $\begin{array}{l}\text { T1: Creative self- } \\
\text { efficacy }\end{array}$ & $\begin{array}{l}\text { The belief of being capable } \\
\text { of producing creative ideas. }\end{array}$ \\
\hline $\begin{array}{l}\text { T2: Complexity } \\
\text { and application }\end{array}$ & $\begin{array}{l}\text { The barrier to transfer the } \\
\text { principles of creative work } \\
\text { into every-day work. }\end{array}$ \\
\hline $\begin{array}{l}\text { T3: Organizational } \\
\text { structure }\end{array}$ & $\begin{array}{l}\text { The belief that creative work } \\
\text { is possible. }\end{array}$ \\
\hline T4: Mindset & $\begin{array}{l}\text { The belief that creative work } \\
\text { is allowed and desired. }\end{array}$ \\
\hline
\end{tabular}

Table 2. Thematical Overview

Creativity and self-efficacy. These two concepts (T1) emerged when discussing the results of the two ideation tasks. The participants refined the common understanding of creativity as something which can be learned and practiced. Here, the participants reported what was helpful to produce more ideas and what was not helpful. Complexity and application as theme (T2) involved different aspects of the application of creativity and ideation in the setting of the public sector. This theme deals with aspects of transferring creativity in the context of public sector organizations. Clearance (T3) refers to aspects of the implementation in the respective organization and the daily business. This can be about resources (time, staff, etc.) or about constraints such as laws or rules. Mindset (T4) deals with cultural aspects in public sector organizations, such as openness towards new solutions, leadership or socio-cultural aspects and demographic variables.

\subsection{Creative Self-efficacy}

In the second phase we made the following core observations:

Self-efficacy. The presented visual stimuli of design heuristics enhanced the creative outcome (quantity of ideas) in three of four cases (quantity first task without stimuli / quantity second task with stimuli: 13/12, 15/17, 9/13, 7/12). One interviewee told us: "I think it's basically already helpful. It was the external circumstances that maybe influenced it a little bit with me. But I think it's basically helpful."

Creativity stimulation and support. The interviewees reported that the icons themselves were not sufficient for being creative and were only helpful in combination with the explanatory text. Dealing with the heuristics led to a higher cognitive load. One participant said: "In addition, the heuristics were helpful, although they always give cause for reflection, which of course takes time and is not necessarily target-oriented." And "I honestly did not look at the icons at all, only at the text."

\subsection{Complexity and Application}

Complexity. While the ideation task was abstract and restricted to a simple task, the context related aspects increased complexity. The complexity and the application of creative work method seems to be hard. One interviewee highlighted: "However, I find it difficult ad hoc to link this to a concrete example."

Application. However, the participants made some promising suggestions, where creative work methods could be applied. One idea was about designing processes. One employee told us: "I believe that the topic of process management in general is not yet a major issue in many administrations. That's why there should be potential for creativity techniques in many areas, because I don't think that processes are really being tackled as much as they are with digital possibilities. How they could be repositioned now, and it depends on whether you are creative and look at your processes from a different perspective." We know some examples of service design thinking and design thinking of processes. This has already been applied in some cases $[22,41]$ and seems to be interesting on a more general basis, too.

\subsection{Organizational Structure}

Organizational structure. The theme refers to the freedom of employees to try out new techniques and methods. In the public sector, we often face policies and 
alignments between state, province, district, and the municipalities. This leads to the view of a limited scope for design at the individual level. The theme organizational structure consists of three sub-themes: clear definitions, clear regulations, and perspectivetaking.

Clear definitions. While the one participant reported one potential application of creative techniques in designing governmental processes, other participants reported some constraints. It was said that "In my eyes, there are areas where this could take up more room and in others, processes are so clearly defined that this cannot offer so much help."

Clear regulations. Regulations were reported as constraints. However, there is a potential fields of action where they see a potential application - culture and tourism. One of the participants concluded: "So if you look at certain specialist applications, for example in the Citizens' Office, where the processes are digitally supported, but where the procedures are already clearly regulated, the scope is not quite as great as when you say that you are doing something completely new for the [...] museum, where everything is still open as to how culture can be communicated digitally in the future. There is a lot of room for manoeuvre and in other areas, because there are so many specifications regarding the procedures, you would have to find niches where it might be possible to provide support." "I believe that the areas that are less regulated, culture but also tourism, are definitely areas where this can work better than in the real estate cadastre or the environmental office, i.e. where the processes are generally very strongly regulated."

Perspective-taking. We could also identify a driver for using creative techniques in the public sector. As every employee is actually also a citizen, it is hard to change the perspective when it is about designing new services, processes, business models or even strategies. "I believe that everything that has a perspective on citizens simply has an additional perspective from which to look at it, and that creativity techniques can work well in these areas. Because then it has a kind of application and an additional external perspective. That creates space for creativity. " Creative techniques are reported as promising when taking the perspective of citizens in order to enhance user-centricity.

\subsection{Mindset}

The theme mindset deals with the attitude and the culture in government. The context-specific circumstances in government lead to some special aspects. For example, creative work can be hindered by the fact that one organization is just one of hundreds with similar problems. Why should they start to question existing solutions? "Situations often have to follow laws that dictate what to do, but the laws usually dictate what has to be done, but not how it has to be done. The question is how to build something like this, how can it look like at all, and the whole issue of intermunicipal cooperation is always involved to some extent, so that people from the same specialist offices in other municipalities think about such processes. You have more people and resources to think about creativity techniques." On the other hand, the same aspect has a positive stance. The high amount of other municipalities that are open for cooperation and for the scaling of solutions, can be a driver.

Management in the sense of public value creation and public welfare is different to private sector with its commercial orientation. Employees in the public sector act in the role of a multi-stakeholder representative. This can be a hard fact when it comes to impede cultivating new work methods. "We always have these resource problems. Budgetary security concept, lack of financial, time and personnel resources... You have to sell these free spaces very well and then you have to show how productive something is when we invest something. A start-up has a better chance of creating this kind of freedom, saying that we try something completely new and we go crazy and we do something and if it goes wrong, then it has gone wrong. That has to reach us first. But we are dealing with tax money. For us, we don't think it's like saying, come on, let's experiment and let it run into the wall and then we'll take a look and say oh yes, too bad."

\subsection{Drivers and Barriers}

In our study, we identified several entry points for different drivers and barriers to cultivate individual creativity in public sector. In this chapter we show our results and categorize them into process, person, product, and press or environment.

\begin{tabular}{|l|l|}
\hline Category & Drivers and Barriers \\
\hline Process & $\begin{array}{l}\text { Applying creative methods in } \\
\text { problem solving is complex. A } \\
\text { clear process could help. } \\
\text { Methods like design thinking } \\
\text { with a structured process can } \\
\text { be a driver and help to foster } \\
\text { individual creativity. }\end{array}$ \\
\hline Person & $\begin{array}{l}\text { Public sector employees are } \\
\text { not trained to generate } \\
\text { disruptive ideas or concepts. } \\
\text { CSS or teaching strategies like } \\
\text { design heuristics/principles }\end{array}$ \\
\hline
\end{tabular}




\begin{tabular}{|l|l|}
\hline Product & $\begin{array}{l}\text { can help foster individual } \\
\text { creative self-efficacy. }\end{array}$ \\
\hline $\begin{array}{l}\text { Public sector employees act in } \\
\text { the sense of public value. The } \\
\text { product (e.g., a new digital } \\
\text { service) needs to be defined } \\
\text { and the task has to be clearly } \\
\text { articulated in order to foster } \\
\text { individual creativity. Also, the } \\
\text { user-centricity (of the user who } \\
\text { will use the product) should be } \\
\text { part of the task. }\end{array}$ \\
\hline Press & $\begin{array}{l}\text { In an environment, where } \\
\text { innovation does occur rather } \\
\text { by chance, than systematically, } \\
\text { encouraging a mindset that } \\
\text { fosters creativity helps to } \\
\text { increase individual creativity. }\end{array}$ \\
\hline
\end{tabular}

Table 3. Drivers and Barriers

\section{Discussion}

Our research and the preliminary findings are just a small first step on the route of understanding drivers and barriers of creative techniques and methods in local governments. However, the represented findings serve several implications for both, theory and practice.

Our initial step contributes to theory by understanding what kind of stimuli can be helpful in order to support creativity. It thus contributes to the body of knowledge about Creativity Support Systems (CSS). Adapting the design heuristics to the context of the respective domain (i.e. the public sector) will help better apply them. Second, we seek to study the drivers and barriers of individuals when it comes to adopt new work methods. By understanding which drivers and barriers determine the adoption of creative problemsolving tasks, we contribute to the state of research in innovation management in public sector organizations. Based on the statements of the participants one can see that the employees in a government are in a dilemma situation. On the one hand, they manage tax money and have no task and only few opportunities to experiment. On the other hand, this does not lead to innovative solutions. It can be valuable for future research to see to find out to what extent the decisions of the employees regarding their working methods (e.g. willingness to experiment and take risks) are influenced by cognitive biases (e.g. projection bias: A projection bias or 'presentism' [10] occurs when a decision-maker projects the present into assumptions about the future [21]. This bias leads to decisions which neglect events that differ from the present, e.g., extreme events like pandemics). Moreover, uncertainty and complexity are not yet fully taken into account. Due to the complexity and uncertainty of social phenomena, it is not possible for employees to make purely rational decisions. Therefore, employees have to rely on heuristics and run the risk of not making optimal decisions due to cognitive distortions. If the public sector is not able to experiment, social innovations will fail to arise and then to materialize. This provides a point of reference for research on bounded rationality.

The implications for practice are various. Our results represent different links to the use of creative techniques in governments. Employees assume that creative techniques application can be beneficial in the fields of action of tourism and culture. While we also show implications that creative techniques can be used more general when it is about processes design and taking the perspective of citizens. All barriers we identified can be a starting point by asking how to determine them. For instance, cooperation is an implication with practical relevance, by working together on problems governments share. Another implication for practice is the aspect to question the regulations and definitions. Some findings suggest that not every regulation and definition is a barrier. Maybe there can be more space to design new processes by implementing clear rules. We also expect that the introduction to design heuristics (e.g., via webinar, podcast, etc.) will lead to a higher creative self-efficacy. Public sector employees will trust their ability to find creative solutions after understanding that creative skills can be learned.

Besides our preliminary findings, our research has some weakness. The explorative qualitative interview is just a first and initial step. The sample size $(n=4)$ is sufficient as a starting point, however, the findings are not to be understood in generalizing fashion. The project the participants were part of and consequently the common goals and shared perspective of the participants might have also limited our insights. Furthermore, there are general limitations of focus groups such like biases due to group interaction and social desirability.

As our investigation is designed just as a first step, there are several possibilities for further research. A semi-structured interview seems to be promising to validate our findings from different perspectives. Second, quantitative data (e.g. a survey) can help to understand how to cultivate creativity in a broader context. Third, a laboratory experiment can help understand the drivers and barriers on the individual level in detail.

\section{References}

[1] Alarifi, S., and A. Althonayan, "The Effects of Transformational Leadership on Followers' Creativity in Public Sector", 2013, pp. 8. 
[2] Allen, B., L.E. Tamindael, S.H. Bickerton, and W. Cho, "Does Citizen Coproduction Lead to Better Urban Services in Smart Cities Projects? An Empirical Study on E-Participation in a Mobile Big Data Platform", Government Information Quarterly 37(1), 2020, pp. 101412.

[3] Angelidou, M., "Smart Cities: A Conjuncture of Four Forces", Cities 47, 2015, pp. 95-106.

[4] Brown, T., "Design Thinking", Harvard business review 86(6), 2008, pp. 84.

[5] Carlgren, L., I. Rauth, and M. Elmquist, "Framing Design Thinking: The Concept in Idea and Enactment", Creativity and Innovation Management 25(1), 2016, pp. 38-57.

[6] Couger, J.D., L.F. Higgins, and S.C. McIntyre, "(Un) Structured Creativity in Information Systems Organizations.", Mis Quarterly 17(4), 1993.

[7] Crosby, B., P. Hart, and J. Torfing, "Public Value Creation Through Collaborative Innovation", Public Management Review, 2016, pp. 1-15.

[8] Eisenhardt, K.M., "Building Theories from Case Study Research", Academy of Management Review 14(4), 1989, pp. 532-550.

[9] Giffinger, R., "European Smart Cities: The Need for a Place Related Understanding”, (2011).

[10] Gilbert, D.T., M.J. Gill, and T.D. Wilson, "The Future Is Now: Temporal Correction in Affective Forecasting", Organizational Behavior and Human Decision Processes 88(1), 2002, pp. 430-444.

[11] Hayter, C.S., "Public or Private Entrepreneurship? Revisiting Motivations and Definitions of Success Among Academic Entrepreneurs", The Journal of Technology Transfer 40(6), 2015, pp. 1003-1015.

[12] Hess, T., C. Matt, A. Benlian, and F. Wiesböck, "Options for Formulating a Digital Transformation Strategy", MIS Quarterly Executive 15, 2016, pp. 103-119.

[13] Hollands, R.G., "Will the Real Smart City Please Stand Up?: Intelligent, Progressive or Entrepreneurial?", City 12(3), 2008, pp. 303-320.

[14] Hung, S.-C., and Y.-Y. Chu, "Stimulating New Industries From Emerging Technologies: Challenges for the Public Sector", Technovation 26(1), 2006, pp. 104-110.

[15] Kelley, T., and D. Kelley, "Reclaim your Creative Confidence.", Harvard business review 90(12), 2012, pp. $115-8$.

[16] Kim, H.M., and S.S. Han, "Seoul", Cities 29(2), 2012, pp. $142-154$.
[17] Klinker, K., M. Wiesche, and H. Krcmar, "Supporting Creative Processes with IT: A literature review”, 2018, pp. 13.

[18] Kummitha, R.K.R., "Smart Technologies for Fighting Pandemics: The Techno- and Human- driven Approaches in Controlling the Virus Transmission", Government Information Quarterly, 2020, pp. 101481.

[19] Liedtka, J., "Perspective: Linking Design Thinking with Innovation Outcomes through Cognitive Bias Reduction", Journal of Product Innovation Management 32(6), 2015, pp. 925-938.

[20] Liedtka, J., R. Salzman, and D. Azer, Design Thinking for the Greater Good: Innovation in the Social Sector, Columbia University Press, 2017.

[21] Loewenstein, G., and E. Angner, "Predicting and Indulging Changing Preferences", Time and decision: Economic and psychological perspectives on intertemporal choice, 2003, pp. 351-391.

[22] Mergel, I., "Digital Service Teams in Government", Government Information Quarterly 36(4), 2019, pp. 101389.

[23] Mergel, I., Y. Gong, and J. Bertot, "Agile Government: Systematic Literature Review and Future Research", Government Information Quarterly 35(2), 2018, pp. 291-298.

[24] Müller, S.D., and F. Ulrich, "Creativity and Information Systems in a Hypercompetitive Environment: A Literature Review.", Communications of the Association for Information Systems 32, 2013.

[25] Nam, T., and T.A. Pardo, "Smart City as Urban Innovation: Focusing on Management, Policy, and Context", Proceedings of the 5th International Conference on Theory and Practice of Electronic Governance - ICEGOV '11, ACM Press (2011), 185.

[26] Nijstad, B.A., C.K.W. De Dreu, E.F. Rietzschel, and M. Baas, "The Dual Pathway to Creativity Model: Creative Ideation as a Function of Flexibility and Persistence", European Review of Social Psychology 21(1), 2010, pp. 3477.

[27] O'hEocha, C., X. Wang, and K. Conboy, "The Use of Focus Groups in Complex and Pressurised IS Studies and Evaluation using Klein \& Myers Principles for Interpretive Research", Information Systems Journal 22(3), 2012, pp. 235256.

[28] Onarheim, B., and M. Friis-Olivarius, "Applying the Neuroscience of Creativity to Creativity Training", Frontiers in Human Neuroscience 7, 2013.

[29] Rhodes, M., “An Analysis of Creativity”, The Phi Delta Kappan 42(7), 1961, pp. 305-310.

[30] Rittel, H.W., and M.M. Webber, "Wicked Problems", Man-made Futures 26(1), 1974, pp. 272-280. 
[31] Schröter, E., and H. Wollmann, "New Public Management", In Handbuch zur Verwaltungsreform. Springer, 2005, 63-74.

[32] Seidel, S., F. Müller-Wienbergen, and J. Becker, "The Concept of Creativity in the Information Systems Discipline: Past, Present, and Prospects", CAIS 27, 2010, pp. 14.

[33] Shearmur, R., "Are Cities the Font of Innovation? A Critical Review of the Literature on Cities and Innovation", Cities 29, 2012, pp. S9-S18.

[34] Sirendi, R., and K. Taveter, "Bringing Service Design Thinking into the Public Sector to Create Proactive and UserFriendly Public Services", In F.F.-H. Nah and C.-H. Tan, eds., HCI in Business, Government, and Organizations: Information Systems. Springer International Publishing, Cham, 2016, 221-230.

[35] Stahl, B.C., M.C. Tremblay, and C.M. LeRouge, "Focus Groups and Critical Social IS Research: How the Choice of
Method can promote Emancipation of Respondents and Researchers", European Journal of Information Systems 20(4), 2011, pp. 378-394.

[36] Torfing, J., "Collaborative innovation in the public sector: the argument", Public Management Review 21, 2019.

[37] Tushman, M.L., "Ambidexterity as a Dynamic Capability: Resolving the Innovator's Dilemma.", pp. 62.

[38] Uebernickel, F., W. Brenner, B. Pukall, T. Naef, and B. Schindlholzer, Design Thinking: Das Handbuch, Frankfurter Allgemeine Buch, 2015.

[39] World Health Organization, and World Health Organization, "Report of the WHO-China joint mission on coronavirus disease 2019 (COVID-19)", 2020.

[40] “Open Government Products”, https://open.gov.sg/

[41] "KGSt | KGSt®-Offensive 'Service Design",, https://www.kgst.de/service-design 